\title{
Immunity and immunopathology to viruses: what decides the outcome?
}

\begin{abstract}
Barry T. Rouse* and Sharvan Sehrawat
Abstract | Many viruses infect humans and most are controlled satisfactorily by the immune system with limited damage to host tissues. Some viruses, however, do cause overt damage to the host, either in isolated cases or as a reaction that commonly occurs after infection. The outcome is influenced by properties of the infecting virus, the circumstances of infection and several factors controlled by the host. In this Review, we focus on host factors that influence the outcome of viral infection, including genetic susceptibility, the age of the host when infected, the dose and route of infection, the induction of anti-inflammatory cells and proteins, as well as the presence of concurrent infections and past exposure to cross-reactive agents.
\end{abstract}

Humans may be infected by and suffer clinical consequences from numerous different viruses, and in most instances the infection is resolved with or without tissue damage. Reinfection is usually subclinical, and for many viruses we have effective vaccines; classic examples include measles, mumps, rubella, rotavirus and varicella zoster viruses. Other viruses, such as $\mathrm{HIV}$, hepatitis $\mathrm{C}$ virus (HCV), hepatitis B virus (HBV) and some herpesviruses, can cause substantial tissue damage in some or all individuals they infect, and lesions can become chronic. These viruses usually have one or more properties that allow them to diminish the efficacy of host adaptive or innate immunity, and we lack effective vaccines against most of these agents. Infection with viruses such as influenza virus and respiratory syncytial virus (RSV) has a variable outcome. Most individuals may suffer mild or subclinical infection, but others experience severe disease that can be lethal. Of particular interest are agents such as West Nile virus, dengue virus and poliovirus that can cause severe disease, but only in a small minority of infected people. Finally some viruses, such as coxsackie B virus, human T lymphotropic virus, Epstein-Barr virus (EBV) and possibly rubella virus, are thought to act as triggering agents for autoimmune diseases and cancer in genetically susceptible individuals. The topic of virus-associated complications has been reviewed by others ${ }^{1,2}$ and will not be discussed here.

In this Review, we discuss our current understanding of the circumstances of infection and host-controlled factors that could explain why an infection can be resolved with minimal impact or cause substantial tissue damage. Understanding such issues could prove to be useful in the future for the control and perhaps prevention of tissue-damaging virus infection.
Tissue damage caused by the immune system

Almost all virus infections cause the recruitment and activation of inflammatory cell types - particularly macrophages and, in some infections, neutrophils that in turn release a range of molecules that induce tissue damage or malfunction. These include cytotoxic cytokines, cationic proteins, lipid mediators, metalloproteinases and components of the oxygen burst. The reactive oxygen species that accumulate in the mitochondria may further contribute to tissue damage ${ }^{3}$. Both innate and adaptive immune signalling events are involved in mediating tissue damage.

Contribution by innate immune responses. Invading viruses and their replicative intermediates can be recognized by several innate immune receptors expressed either at the host cell surface or within cells. Many types of innate immune receptor can participate in the immune response but, in virus infections, the most studied are the Toll-like receptors (TLRs), retinoic acid-inducible gene I (RIG-I; also known as DDX58) and NOD-like receptors (NLRs). Virus infections usually activate the endosomal TLRs (TLR3, TLR7, TLR8 and TLR9) that recognize viral nucleic acids and double-stranded RNA intermediates ${ }^{4}$. The cytoplasmic RIG-I-like receptors recognize viral genomic RNA or RNA encoded by genomic DNA, whereas the NLRs recognize viral DNA genomes (reviewed in REF. 5). In general, activation of many of these receptors causes the production of pro-inflammatory cytokines and interferons (IFNs), as well as signals that recruit and activate cells involved in inflammation and the induction of adaptive immunity. The pattern of innate 
immune events induced after the entry of virus may dictate the outcome of infection. Many viruses that persist trigger innate cells such as dendritic cells (DCs), natural killer (NK) cells and macrophages to produce anti-inflammatory molecules such as interleukin-10 (IL-10) and transforming growth factor- $\beta$ (TGF $\beta$ ). For example, DCs from lymphocytic choriomeningitis virus (LCMV)-infected mice produce high levels of IL-10 (REF. 6), and IL-10 is produced by monocytes from individuals infected with $\mathrm{HIV}, \mathrm{HCV}$ or $\mathrm{HBV}^{7-9}$. Following RSV infection, the interaction between the virus and lung plasmacytoid DCs (pDCs) is crucial, as the removal of pDCs before infection favours an immunopathological reaction in the lungs ${ }^{10}$. A damaging response to a virus infection is more likely to occur with viruses that can interfere with one or more innate defences. Some examples of viruses that have this effect and the innate defence mechanism that is diminished are listed in TABLE 1.

Contribution by adaptive immune responses. Once adaptive immune effector cells are generated, these can contribute to tissue damage. T cells, for example, can directly destroy virus-infected cells or release cytokines, such as tumour necrosis factor (TNF), that damage cells. With some non-cytopathic virus infections, such as HCV and HBV, destruction of infected cells by $\mathrm{CD}^{+}$effector $\mathrm{T}$ cells is the main cause of damage to the liver ${ }^{11,12}$ (BOX 1; FIG. 1). Responses to infected cells by different types of $\mathrm{CD} 4^{+} \mathrm{T}$ cell orchestrate a tissuedamaging inflammatory reaction and these become

Plasmacytoid DC

A dendritic cell (DC) subset with a morphology that resembles that of a plasmablast. Plasmacytoid DCs produce large amounts of type I interferons in response to viral infection.

Resolvins

Resolution-phase interaction products that are made by the host from eicosapentaenoic acid (EPA) and

docosahexaenoic acid (DHA) and that have

anti-inflammatory properties.

Galectins

A family of lectin proteins

that bind a wide variety of

glycoproteins and glycolipids

containing $\beta$-galactosides

through their carbohydrate-

recognition domain. They have

extracellular and intracellular

functions, including the

regulation of apoptosis, RAS

signalling, cell adhesion and

angiogenesis.

Regulatory $\mathrm{T}\left(\mathrm{T}_{\mathrm{Reg}}\right)$ cells A subset of $\mathrm{T}$ cells that control the activity of effector $\mathrm{T}$ cells under inflammatory or steady state conditions. chronic against persistent viruses. Most often, the cell subsets involved are $\mathrm{T}$ helper $1\left(\mathrm{~T}_{\mathrm{H}} 1\right)$ cells, but $\mathrm{T}_{\mathrm{H}} 17$ cells may contribute to inflammatory responses during HIV, HCV and influenza virus infections ${ }^{13-15}$. In such $\mathrm{T}_{\mathrm{H}} 17$ cell-driven responses, neutrophils are recruited and become a major source of tissue-damaging molecules. $\mathrm{T}_{\mathrm{H}} 2$ cells are rarely associated with inflammatory responses during viral infections, but a $\mathrm{T}_{\mathrm{H}} 2$ cell response can occur during severe lung responses to RSV infection ${ }^{16}$.

Antibody responses to viruses may also contribute to tissue damage. This occurs when antibody binds to an infected cell, activates complement and causes an inflammatory reaction. Alternatively, antibodymediated inflammatory reactions involve toxicity following engagement of IgG with Fc receptors on inflammatory cells, which causes inflammatory mediator release ${ }^{17}$, or following deposition of viral antigen-antibody complexes in capillary beds, leading to activation of the complement cascade. Lesions formed by immune complex deposition can occur when viruses persist and poorly neutralizing IgG is produced; lesions include nephritis, polyarteritis and arthritis. Immune complex lesions were first reported in LCMV infection but have also been reported in chronic HCV and HBV infection, as well as in idiotypic IgA nephropathy associated with HIV infection ${ }^{18-21}$. Viruses such as RSV express antigens that may induce an IgE response and type I hypersensitivity might partially account for lung lesions in some children infected with RSV ${ }^{22}$.
Despite these possible occurrences, tissue damage is modest in most cases of viral infections; however, the level of tissue damage can vary between individuals infected with the same virus. In the following section, we describe the host responses that function to minimize tissue damage.

\section{Host factors that limit tissue damage}

The host can use many countermeasures to limit tissue damage after virus infection. These tissue-protective events are more effective against some viruses and some circumstances of infection than others, accounting for the different pattern of response observed among individuals. The countermeasures include the production of cytokines such as IL-10 and TGF $\beta$ that have anti-inflammatory activity, other host-derived anti-inflammatory mediators such as resolvins and galectins, the activity of cell subsets that inhibit other cells from mediating inflammatory events, as well as the induction of molecules on effector cells that result in the loss of effector functions (FIG. 2).

Anti-inflammatory cytokines. The two best-known cytokines that inhibit inflammatory reactions are IL-10 and TGF $\beta$. Many cell types can produce IL-10, including subsets of activated DCs, macrophages (when infected with some viruses), activated regulatory $T\left(T_{\text {Reg }}\right)$ cells, B cells and some subsets of NK cells following stimulation with TLR ligands ${ }^{23}$. Although some viruses, such as EBV and cytomegalovirus (CMV), produce an IL-10like molecule that functions in vitro in a similar manner to host IL-10, it is still not clear if this viral IL-10 has any role during viral infections in vivo ${ }^{24,25}$. Host-derived IL-10 can block pro-inflammatory cytokine and chemokine production and MHC class II expression, and it can also interfere with many signalling pathways that result in pro-inflammatory cytokine production. For example, nuclear factor- $\kappa \mathrm{B}(\mathrm{NF}-\kappa \mathrm{B})$ signalling is inhibited by IL-10-mediated induction of p50 and p105 NF- $\kappa B$ subunits, one of which ( $\mathrm{p} 50$ ) binds to the stimulatory subunit p65, sequestering it in the cytoplasm and making it unavailable for binding to the promoters of IL- 6 and CC-chemokine ligand 3 (also known as MIP1a) for their transcription (reviewed in REF. 26). IL-10 also suppresses type I IFN-induced tyrosine phosphorylation of signal transducer and activator of transcription 1 (STAT1) and also induces the expression of suppressor of cytokine signalling 3 (SOCS3) by macrophages and neutrophils, which impairs their inflammatory activity.

The extent of IL-10 production during an infection could influence the amount of tissue damage that occurs. Thus, if the IL-10 response is absent, owing to genetic mutation, or is artificially suppressed by antibodies specific for IL-10 or its receptor, inflammatory reactions to infectious agents may be exaggerated. For example, mice lacking an IL-10 response develop more severe inflammatory reactions to ocular infection with herpes simplex virus (HSV) than do normal controls ${ }^{27}$. IL-10 may be of particular importance to constrain the severity of inflammatory reactions caused by chronic infections, and its anti-inflammatory function has been shown during infection with viruses such as HCV and HIV ${ }^{9,28,29}$. 


\section{Table 1 | Virus and host features that favour tissue damage}

Feature

Viral evasion strategies

Interference with innate immune responses

Interference with antigen processing and presentation

Infidel replication
machinery and variants
Viral homologues of host
regulatory proteins

\section{Dose of infection*}

High

Influenza virus
LCMV

Low HBV

LCMV

HIV

$\mathrm{HCV}$, HIV and influenza virus

CMV

EBV

Effect on host

$\mathrm{HCV}$

Blocks RIG-I pathway by degrading IPS1

NS1 protein inhibits RIG-I by direct interaction

$V$ protein inhibits RIG-I by interacting with MDA5

Inhibit IRF3

Viral RNA is undetectable by PRRs owing to removal of $5^{\prime}$ triphosphates

ICP47 blocks TAP-mediated peptide transport

US3 inhibits tapasin; US6 blocks TAP-mediated peptide transport; gp40 retains MHC class I molecules in ER; pp65 prevents activation of IRF3

EBNA1 inhibits the proteasome; IL-10 homologue downregulates MHC class II expression

Nef protein inhibits cell surface expression of CD4 and MHC class I molecules

Escape removal by antibodies and CTLs and emergence of variants

CMV IL-10-like protein competes with host IL-10 for binding IL-10 receptor

IL-10 homologue; EBI3 protein related to $\mathrm{p} 40$ subunit of IL-23 and IL-27

Immunopathology of the liver

Inadequate $\mathrm{CD} 8^{+} \mathrm{T}$ cell response

Induces CTL exhaustion

Immunopathology of the liver

Choriomeningitis

\section{Route or location of infection}

\begin{tabular}{ll} 
Intratracheal & Reovirus \\
\hline Oral versus footpad & Reovirus \\
\hline $\begin{array}{l}\text { Intracranial versus } \\
\text { intravenous }\end{array}$ & LCMV
\end{tabular}

\section{Host genetic susceptibility}

Defective type I and II IFNs

Poliovirus

HSV and VZV

TLR3 polymorphism or deficiency

HSV-1 and VZV

WNV

Influenza virus

TLR2 polymorphism

HSV-2

HLA-DR7 versus HLA-DR2

HBV

CCR5 $532 b p \quad H I V$

HLA-B35 versus HLA-B57 HIV

HLA complex P5 rs2395029 HIV

HLA-C 5' region 9264942 HIV

HLA-DQB1*031 and HCV

HLA-DRB $1{ }^{*} 11$

IL-28B polymorphism

$\mathrm{HCV}$

MXA, OAS1 and PKR

polymorphisms
$\mathrm{HCV}$
Virus-specific $\lg A$ and double-positive $\left(C D 4^{+} C D 8^{+}\right) T$ cell responses

Restricted $\mathrm{CD} 8^{+} \mathrm{T}$ cell repertoire induced by oral infection

$\mathrm{CD}^{+} \mathrm{T}$ cell-mediated lethal choriomeningitis occurs on intracranial infection and viral persistence occurs on intravenous infection

Increased susceptibility to paralysis

Increased susceptibility to encephalitis

Increased encephalitis

74,112

Decreased encephalitis

Decreased acute pneumonia

Increased genital lesions and viral shedding

Chronic carrier versus viral clearance

Resistance to macrophage-infecting virus

Rapid versus delayed progression to AIDS

$\Pi$ versus GG genotype: high versus lower viral load at set point

$\Pi$ versus CC genotype: high versus lower viral load at set point

Spontaneous resolution

CC genotype associated with spontaneous resolution and response to treatment, TT genotype associated with persistent infection and poor response to treatment

Tा genotype at -88 in MXA, GG genotype in 3' UTR of OAS1 and CT genotype at -168 of $P K R$ give rise to self-limiting disease 
Table 1 (cont.) | Virus and host features that favour tissue damage

\begin{tabular}{|c|c|c|c|}
\hline Feature & Virus & Effect on host & Refs \\
\hline \multicolumn{4}{|c|}{ Age when infected } \\
\hline Young & Influenza virus and RSV & $\begin{array}{l}\text { Increased susceptibility to infection (in RSV because of } \\
\text { inadequate type } 1 \text { immune response) }\end{array}$ & 138,139 \\
\hline Adult & $E B V, V Z V$, measles virus and mumps virus & Increased susceptibility to infection & 72,101 \\
\hline Old & VZV, CMV, RSV and influenza virus & Increased susceptibility to infection & 81,138 \\
\hline Flaviviruses & Dengue virus & DHF or DSS & 100 \\
\hline \multicolumn{4}{|c|}{$\begin{array}{l}\text { CCHFV, Crimean-Congo haemorrhagic fever virus; CCR5, CC-chemokine receptor 5; CMV, choriomeningitis virus; CTL, cytotoxic Tlymphocyte; DHF, dengue } \\
\text { haemorrhagic fever; DSS, dengue shock syndrome; EBI3, EBV-induced gene 3; EBNA1, Epstein-Barr virus nuclear antigen 1; EBV, Epstein-Barr virus; } \\
\text { ER, endoplasmic reticulum; HBV, hepatitis B virus; HCV, hepatitis C virus; HSV, herpes simplex virus; ICP47, infected cell protein 47; IFN, interferon; } \\
\text { IL, interleukin; IPS1, IFNB-promoter stimulator 1; IRF3, interferon-regulatory factor 3; LCMV, lymphocytic choriomeningitis virus; Nef, negative factor; } \\
\text { MDA5, melanoma differentiation-associated gene 5; MXA, myxoma resistance protein A; OAS1, 2' } 5^{\prime} \text { oligoadenylate synthetase } 1 \text {; PKR; protein kinase R; } \\
\text { PRR, pattern recognition receptor; RIG-I, retinoic acid-inducible gene I; RSV, respiratory syncytial virus; TAP, transporter associated with antigen processing; } \\
\text { TLR, Toll-like receptor; UTR, untranslated region; VZV, varicella zoster virus; WNV, West Nile virus. *Dose of infection with lentiviruses }{ }^{88} \text {, simian immunodeficiency } \\
\text { virus }^{89} \text { and HCV }{ }^{12} \text { has no effect on the host response. }\end{array}$} \\
\hline
\end{tabular}

Recently, IL-10 production by virus-specific effector $\mathrm{T}$ cells during the acute response to influenza virus was shown to be responsible for minimizing the severity of pulmonary lesions in mice ${ }^{30}$. The responding $\mathrm{CD}^{+} \mathrm{T}$ cells showed plasticity and gained the ability to produce IL-10 in addition to their main effector product, IFN $\gamma$. Inhibiting the response to IL-10 with antibody specific for the IL-10 receptor resulted in more severe and sometimes fatal virus-induced lung damage. IL- 10 production by effector $\mathrm{CD} 8^{+} \mathrm{T}$ cells and the IL-10-induced suppression of IL-2 production by these cells were also shown in HIV-infected patients ${ }^{31}$. Suppression of the effector T cell IL-10 response by lethal strains of influenza virus, such as the 1918 $\mathrm{H} 1 \mathrm{~N} 1$ strain and the H5N1 strain, is thought to contribute to their virulence ${ }^{32}$. In some instances excessive IL-10 production during a virus infection may inhibit a protective effector $\mathrm{T}$ cell response and favour viral persistence $^{6}$. This can happen in some circumstances with LCMV infection and may also occur during HIV infection ${ }^{6,9}$.

The TGF $\beta$ superfamily of cytokines has a similar anti-inflammatory role to IL-10, although the effects of TGF $\beta$ are more complex. These cytokines have a wide range of activities that include both anti-inflammatory and pro-inflammatory effects with the outcome depending on the concentration of TGF $\beta$ available and some other factors ${ }^{33}$. Moreover, TGF $\beta$ superfamily members exist in a latent, inactive form and must be cleaved before they can bind to receptors and mediate their effects on cells. Nevertheless, the extent of TGF $\beta$ production during virus infection could influence whether the response becomes overtly tissue damaging. Accordingly, TGF $\beta$ inhibits several functions of $\mathrm{T}$ cells, including proliferation, differentiation into effector T cells and some effector functions such as cytotoxicity ${ }^{34}$. The inflammatory activities of $\mathrm{CD}^{+}$ T cells, $\mathrm{T}_{\mathrm{H}} 1$ cells and $\mathrm{T}_{\mathrm{H}} 17$ cells, as well as the production of inflammatory products by recruited cells, are all inhibited by TGF $\beta^{34}$.
Most of our knowledge of the role of TGF $\beta$ in microbial pathogenesis concerns non-viral pathogens $^{35,36}$. However, some viruses do cause an increase in TGF $\beta$ levels, and other viruses express proteins that can cleave and activate TGF $\beta$. For example, influenza virus neuraminidase can activate TGF $\beta$, and the extent to which this happens could influence virulence ${ }^{37}$. Among the viruses that cause increased TGF $\beta$ production are chronic infections by HBV and HCV. A nonstructural protein of HCV (NS4) was shown to be responsible for TGF $\beta$ induction and it seems that the magnitude of the TGF $\beta$ response, with IL-10 production, could determine if $\mathrm{HCV}$ infection is effectively cleared or becomes chronic ${ }^{14}$. Acute infection with reovirus may also activate TGF $\beta$ signalling to an extent that correlates with damage to the central nervous system ${ }^{38}$. Of note, virus-specific $\mathrm{CD}^{+} \mathrm{T}$ cells isolated from $\mathrm{HCV}$ infected individuals produce TGF $\beta$ that suppresses virus-specific $\mathrm{T}$ cell responses ${ }^{39}$. Moreover, blockade of TGF $\beta$ enhanced the in vitro activity of T cells ${ }^{39}$. Furthermore, a recent report attributed an intrinsic role of TGF $\beta$ signalling in effector T cells to explain their diminished survival and effector functions during chronic LCMV infection ${ }^{40}$.

IL-10 and TGF $\beta$ are not the only cytokines that can limit damage caused by inflammatory reactions. Recently, for example, IL-17 - a cytokine that is normally associated with the promotion of tissue damage - was shown to have an anti-inflammatory role by suppressing $\mathrm{T}_{\mathrm{H}} 1$ cell-mediated inflammatory effects ${ }^{41}$. The suppressive effect of IL-17 was noted initially with autoimmune lesions but was recently also observed during infection with Theiler's murine encephalomyelitis virus in mice ${ }^{42}$.

Other anti-inflammatory molecules. Several other natural host products can also participate in the control and resolution of inflammatory reactions (FIG. 3). These include the galectins, resolvins and protectins. These molecules contribute to the resolution of inflammatory lesions in several non-infection-related lesions ${ }^{43}$. Members of the 


\section{Box 1 Viruses that persist and cause chronic disease}

Several human viral infections - for example HIV, hepatitis B virus and hepatitis C virus (HCV) - become persistent, and some can cause severe chronic disease that is usually the consequence of an immune reaction to the virus. Many herpesviruses persist but rarely cause chronic disease in normal (immunocompetent) hosts. During HIV infection, the virus is never eliminated from the body, as it integrates into the genome of infected host cells and has several immune evasion strategies. These include antigenic variability, the structure of its envelope, which makes it refractory to neutralizing effect of antibodies, replication in and destruction of $\mathrm{CD} 4^{+} \mathrm{T}$ cells, induction of immune imbalance and induction of expression of inhibitory receptors by $\mathrm{CD} 8^{+} \mathrm{T}$ cells, making the cells functionally ineffective.

$\mathrm{HCV}$ infection causes chronic lesions in $\sim 85 \%$ of infected individuals, but the remaining $\sim 15 \%$ control the infection and clear virus from the liver. $\mathrm{HCV}$ is a non-cytopathic infection that replicates for several weeks before an adaptive immune response occurs. Viral clearance is mediated by $T$ cells, and this causes hepatocyte destruction and mild hepatitis. The virus has several means of inhibiting innate immune mechanisms and the effects of these may relate to whether control of the virus or chronic infection ultimately occurs. The virus-encoded attenuators of the innate immune response include inhibiting type I interferon (IFN) responses at several levels, raising the activation threshold of natural killer (NK) cell activation and having negative effects on dendritic cell maturation and function. Protective immunity is associated with the induction of IFN $\gamma$-producing $C D 8^{+} \mathrm{T}$ cells and high numbers of Thelper 1 cells. Individuals that develop chronic disease instead mount a response comprising interleukin-10 (IL-10)-producing $\mathrm{CD}^{+}$and $\mathrm{CD}^{+} \mathrm{T}$ cells and sometimes forkhead box P3 (FOXP3) regulatory T cells. However, it is not clear what accounts for the different outcome of HCV infection. It has been suggested that dose of exposure, polymorphism of genes affecting NK cell activation and concurrent disease or infections (for example, co-infection of HIV and HCV results in more severe hepatitis). The role of innate and adaptive events that affect HCV pathogenesis has been recently reviewed elsewhere ${ }^{12}$.

galectin family might also help to constrain inflammatory reactions ${ }^{43}$. Galectin 9 , for example, binds to the $\mathrm{T}$ cell immunoglobulin domain and mucin domain protein 3 (TIM3; also known as HAVCR2) on activated effector T cells and causes apoptosis, and at the same time it expands the $\mathrm{T}_{\mathrm{Reg}}$ cell response ${ }^{44-46}$; both effects minimize tissue damage. It is possible that variations in galectin concentrations between individuals could explain why the outcome in some individuals is rapid and protective but in others it is prolonged and causes tissue damage. Currently, there is no evidence for this hypothesis; however, galectin levels are different between HIV- and HCVinfected individuals and controls, and in $\mathrm{HCV}$ infection galectin levels may correlate with viral loads $s^{4748}$.

$T_{\text {Reg }}$ cells. Another mechanism of counteracting excessive tissue damage following virus infection is the induction, activation or expansion of several types of $\mathrm{T}_{\text {Reg }}$ cell, the main activity of which is to inhibit the function of other cell types. The best-studied $\mathrm{T}_{\mathrm{Reg}}$ cells are $\mathrm{CD}^{+} \mathrm{T}$ cells that express the transcription factor forkhead box P3 $(\text { FOXP3 })^{49}$. Such $\mathrm{T}_{\text {Reg }}$ cells could influence the outcome of infection, particularly those that are chronic in nature ${ }^{50}$. In model systems in which the activity of $\mathrm{T}_{\text {Reg }}$ cells can be inhibited, tissue-damaging immunopathological reactions to some viruses are increased. This was observed with the HSV ocular immunopathology model in mice ${ }^{51}$. Similar tissue-protective effects of $\mathrm{T}_{\mathrm{Reg}}$ cells were noted in a Friend retrovirus model, as well as in mouse models of RSV and West Nile virus ${ }^{52,53}$. In the HSV ocular immunopathology model, recent observations showed the therapeutic value of increasing the proportion of FOXP3 ${ }^{+} \mathrm{T}_{\mathrm{Reg}}$ cells to limit virus-induced immunopathological reactions $\mathrm{s}^{54,55}$. This was achieved by administering reagents, such as galectin 9 and the fungal metabolite FTY720, that could cause some conventional $\mathrm{CD}^{+} \mathrm{T}$ cells to convert in vivo into FOXP3 ${ }^{+}$
$\mathrm{CD} 4^{+} \mathrm{T}$ cells that have regulatory functions ${ }^{45,55}$. In several chronic human virus infections, $\mathrm{T}_{\mathrm{Reg}}$ cells are thought to influence the extent of tissue damage, but this view remains debatable and is difficult to evaluate in natural disease situation $\mathrm{s}^{56}$. Some of the most convincing evidence that $\mathrm{T}_{\mathrm{Reg}}$ cells are beneficial in a human chronic viral infection came from observations of the disease outcome in patients accidentally infected with $\mathrm{HCV}$. In this example, it was shown that a favourable outcome was more likely to occur in those individuals that made the highest IL-10-producing $\mathrm{T}_{\mathrm{Reg}}$ cell responses ${ }^{57}$.

The role of inhibitory receptors. An additional mechanism that could affect the pattern of events that follow virus infection is the signalling of inhibitory receptors on effector cells of both innate and adaptive immune systems. Such events may favour tissue damage over infection control. Several negative signalling systems that affect innate immune responses to virus infections have been noted, and many of these function by terminating NF- $\mathrm{BB}$ signalling, which curtails pro-inflammatory cytokine and chemokine production ${ }^{58}$ (BOX 2).

The protective function of effector T cells may also be compromised if they express inhibitory receptors and engage their ligands. The circumstances that result in upregulation of inhibitory receptors by effector $\mathrm{T}$ cells is not fully understood at a mechanistic level, but the effect usually becomes evident during chronic infections, especially those that involve high levels of persistent antigen ${ }^{59}$. Some of the well-characterized receptors that can be induced in chronic infection include programmed cell death 1 (PD1) and the IL-10 receptor. These molecules are expressed at higher levels by $\mathrm{CD} 8^{+} \mathrm{T}$ cells during chronic infection with LCMV in mice ${ }^{6,60}$. Their engagement with their respective ligands impairs effector $\mathrm{T}$ cell function, resulting in a so-called exhaustion phenotype. This exhaustion phenotype for effector $\mathrm{T}$ cells has since been observed in other 


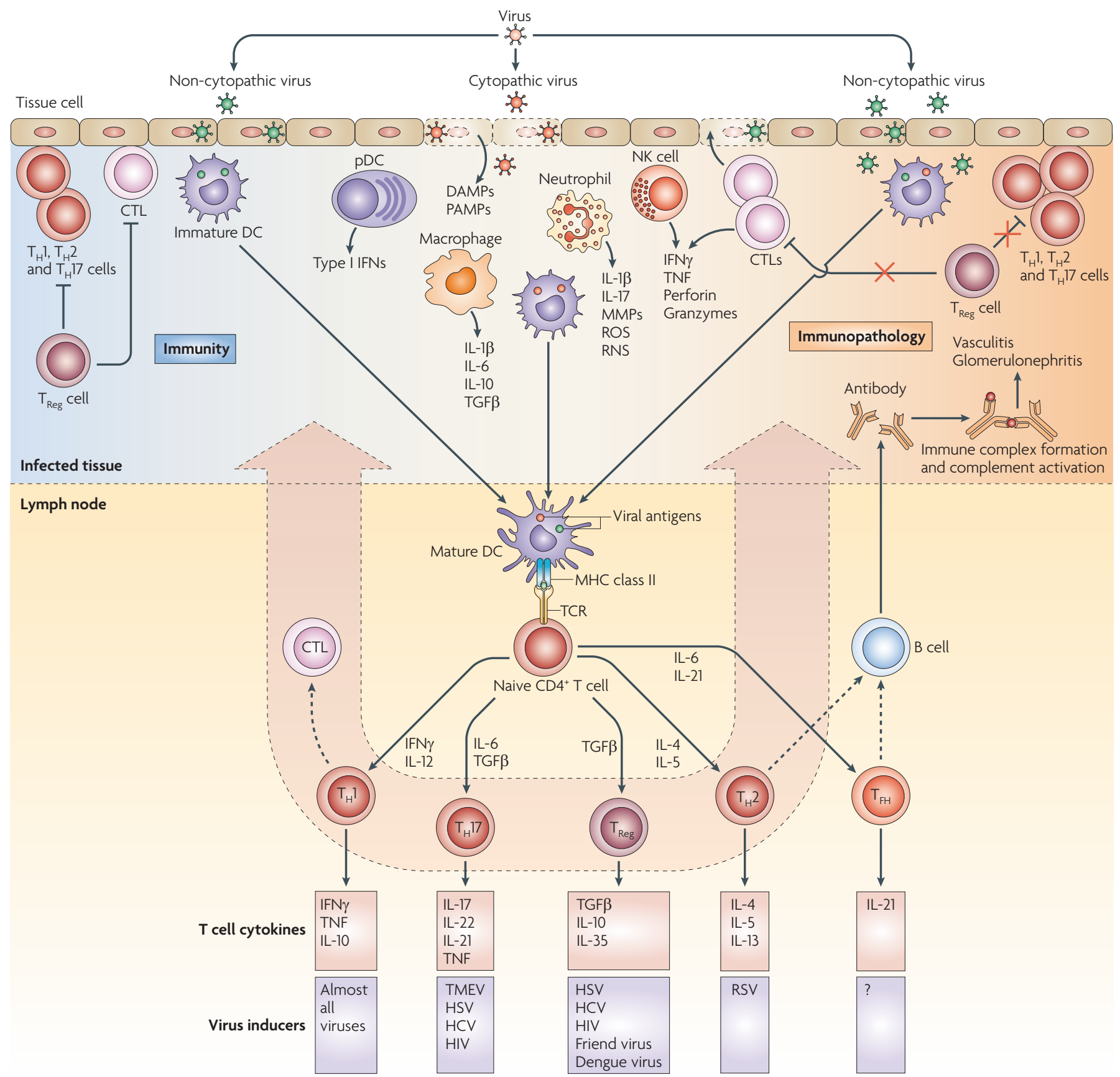

Figure 1 | Immunity or immunopathology following viral infection. Following entry into host cells, viruses (cytopathic or non-cytopathic) replicate at the site of infection. Cytopathic viruses kill infected cells, causing the release of cellular contents, including proteases and lysosomal enzymes, which digest the extracellular matrix and create an inflammatory milieu. Neutrophils that are rapidly recruited to the site of infection release inflammatory mediators. Innate cells recognize viral replication intermediates and secrete pro-inflammatory cytokines, which, in addition to helping to clear the virus, contribute to tissue damage. Viral antigens are taken up by antigen-presenting cells and carried to local draining lymph nodes. Depending on the cytokine milieu created in the draining lymph node, different types of Thelper $\left(\mathrm{T}_{H}\right)$ cell responses are induced. Primed CD8 ${ }^{+}$cytotoxic T lymphocytes (CTLs) migrate to the site of infection and kill virally infected cells, thereby contributing to tissue damage. After migrating to the site of infection, $\mathrm{T}_{H}$ cells also contribute to the tissue damage. In conditions in which the control of aggressive $T_{H}$ cells and CTLs by regulatory $T\left(T_{\text {Reg }}\right)$ cells is impaired and other inhibitory pathways fail to curtail them, tissue damage is the main consequence of viral infection. $T_{H}$ cells also provide help to $B$ cells to secrete antibodies, which form immune complexes that are deposited in certain tissues such as the glomeruli of the kidneys and blood vessels to cause immune complex-mediated disease. DAMP, danger-associated molecular pattern; DC, dendritic cell; HBV, hepatitis B virus; HCV, hepatitis C virus; HSV, herpes simplex virus; IFN, interferon; IL, interleukin; MMP, matrix metalloproteinase; NK, natural killer; PAMP, pathogen-associated molecular pattern; pDC, plasmacytoid DC; RNS, reactive nitrogen species; ROS, reactive oxygen species; RSV, respiratory syncytial virus; $T C R$, T cell receptor; $\mathrm{T}_{\mathrm{FH}}, \mathrm{T}$ follicular helper; TGF $\beta$, transforming growth factor- $\beta$; TMEV, Theiler's murine encephalomyelitis virus; TNF, tumour necrosis factor. 
chronic infections, including HIV, $\mathrm{HCV}$ and $\mathrm{HBV}^{61-63}$. Some recent studies have suggested the existence of a correlation between the PD1-PD1 ligand 1 (PDL1) pathway and the production of IL-10. Thus, triggering of PD1 by PDL1 induced high levels of IL-10 production in monocytes that in turn inhibited the function of $\mathrm{CD}^{+} \mathrm{T}$ cells ${ }^{64}$. The IL-10-mediated inhibition of $\mathrm{CD}^{+} \mathrm{T}$ cell effector function was also shown in chronic LCMV infection in mice ${ }^{6}$. Exhausted T cells may express additional inhibitory receptors that include lymphocyte activation gene 3 (LAG3) and TIM3, with distribution varying in different locations ${ }^{59}$. Ligation of inhibitory receptors on exhausted $\mathrm{T}$ cells diminishes their protective function, allowing viruses to persist and cause more tissue damage. In fact, the TNF-producing ability of exhausted $\mathrm{T}$ cells that contributes to tissue damage

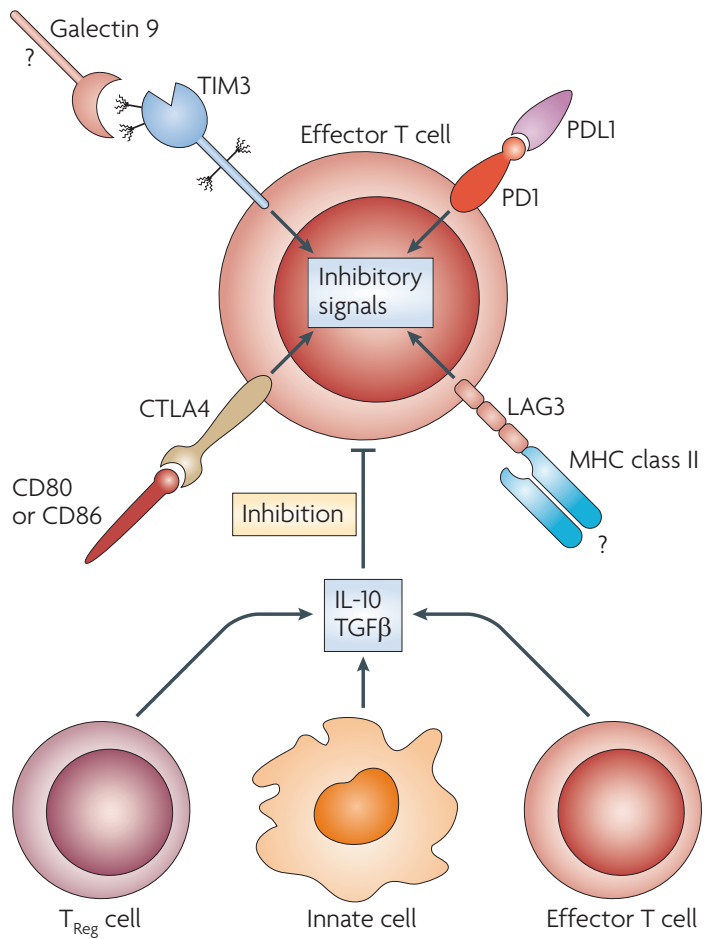

Figure 2 | Inhibitory mechanisms to limit tissue damage caused by T cells. Effector T cells upregulate inhibitory receptors such as programmed cell death 1 (PD1), T cell immunoglobulin domain and mucin domain protein 3 (TIM3), lymphocyte activation gene 3 (LAG3) and cytotoxic T lymphocyte antigen 4 (CTLA4) (and others such as adenosine receptors (not shown)) on their surface. Ligation of these receptors with PDL1, galectin 9, MHC class II molecules and CD80 or CD86, respectively, delivers inhibitory signals to the effector $T$ cells and controls their inflammatory activity and subsequent tissue damage. In addition, activated regulatory $\mathrm{T}\left(\mathrm{T}_{\mathrm{Reg}}\right)$ cells, specialized innate cells or highly polarized effector $T$ cells that can produce anti-inflammatory cytokines inhibit effector T cell responses. Inadequate control exerted by these pathways under some circumstances therefore results in uncontrolled T cell activation and proliferation causing excessive tissue damage. Question marks indicate interactions for which extensive in vivo studies have not been carried out. IL-10; interleukin-10; TGF $\beta$, transforming growth factor- $\beta$. is one of the last functions to wane ${ }^{59}$. It is not clear how infection causes inhibitory receptor upregulation but in some instances a viral component has been implicated (for example, the HCV core protein) and in other cases virus-induced IFNs ${ }^{63,65}$ or TLR ligands expressed by viruses are thought to have a role ${ }^{66}$.

The discovery of the exhaustion phenomenon provides an enticing opportunity for the development of new approaches for improving immunity and controlling the severity of chronic viral infections. Accordingly, blockade of the signals that are responsible for the exhausted state can result in partial recovery of immune function and more effective infection control $^{6,60}$. Initial observations focused on blockade of PD1 or PDL1, as well as the IL-10 receptor, using monoclonal antibodies, but blockade of several inhibitory signals was even more efficacious than blockade of a single component ${ }^{67,68}$. Thus, inhibition of either the PD1-PDL1 interaction and the IL-10 receptor or the PD1-PDL1 interaction and LAG3 provided the best approach to achieve immune recovery and viral control after chronic LCMV infection in mice. Furthermore, when both blockade of the exhaustion pathways and therapeutic vaccinations were carried out, control of chronic LCMV infection was greater than either approach alone ${ }^{69,70}$. It is likely, therefore, that similar strategies might prove to be useful for the control of human chronic infections.

\section{Factors that favour tissue damage}

In this Review, we explore the question of why virus infection has varied outcomes in different individuals infected with the same virus. This issue is particularly difficult to address in the context of sporadic diseases that cause overt disease in only a small minority of infected persons. The classic example of this is paralytic polio, which affects less than $1 \%$ of individuals infected with poliovirus ${ }^{71}$. Reasons for susceptibility to poliovirus-associated disease remain unexplained but one favoured hypothesis is that the involvement of the central nervous system (CNS) is associated with a defect in type I IFN production, allowing robust poliovirus replication in the periphery and spread of the virus to the $\mathrm{CNS}^{71}$. Another example is herpes simplex encephalitis that occurs in adults. This is a rare, often lethal, debilitating disease caused by infection with HSV-1 (REF. 72). The disease usually occurs following reactivation of the host's resident latent virus, although primary infection can occasionally result in encephalitis and is a common outcome in seronegative neonates infected with HSV-2. Lesions of herpes simplex encephalitis in adults are, in part, immune mediated, but why they only occur in an unfortunate few is not known. Primary genetic susceptibility factors have not been implicated nor has the emergence of a neurotropic mutant, although recently a minority of cases of herpes simplex encephalitis in children were associated with polymorphism in the genes encoding TLR3 or UNC93B (which is involved in TLR signalling $)^{73,74}$. In the following section we describe the situations that favour a tissue-damaging response over immune control (TABLE 1). 
a

Pro-inflammatory mechanisms

- Cytokines and chemokines:
IL-2, IFNs, TNF, IL-1 $\beta$, IL-6, IL-8,
IL-12, IL-17, CCL2, CCL3 and CXCL2
- Chemical mediators: prostaglandins,
histamines and cyclooxygenases
- Reactive species: reactive oxygen
species and reactive nitrogen species
- Proteinases: matrix metalloproteinases

Anti-inflammatory mechanisms

- Teg $_{\text {Rells }}$ cell
- Cytokines: IL-10, TGF $\beta$ and IL-35
- Chemical mediators: resolvins, protectins,
galectin 1 and galectin 9
- Inhibitory receptors: PD1, LAG3, TIM3 and CTLA4
- Innate immune regulatory proteins:
TLR signal inhibitors: A20, IRAKM, SOCS1 and SOCS3
RLR regulators: RNFI25, ubiquitin ligase, DUBA, NLRX1
NLR inhibitors: p202

b

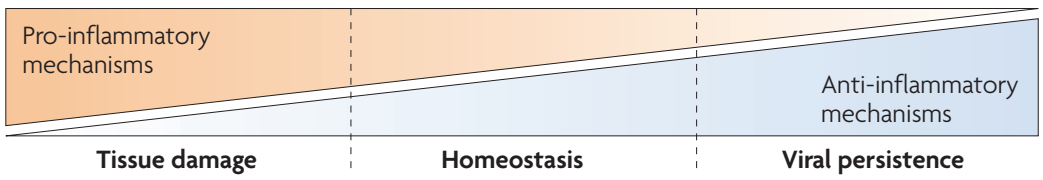

Figure 3 | Balance between pro-inflammatory and anti-inflammatory mechanisms may decide the outcome of viral infection. a |Pro-inflammatory and anti-inflammatory mechanisms induced after viral infection. $\mathbf{b}$ |The balance between immunity and immunopathology following viral infection might depend on the levels of anti-inflammatory and pro-inflammatory mechanisms. A balanced combination of pro-inflammatory and anti-inflammatory mechanisms would facilitate viral clearance and immunity to reinfection, with minimal damage to host tissues. An excess of pro-inflammatory mechanisms would ensure viral clearance but causes tissue damage. If anti-inflammatory mechanisms outweigh pro-inflammatory mechanisms, the pathogen could persist in the host as a subclinical infection, an opportunist or a tissue-damaging agent. CCL2, CC-chemokine ligand 2; CTLA4, cytotoxic T lymphocyte antigen 4; CXCL2, CXC-chemokine ligand 2; DUBA, deubiquitinase enzyme A; IFN, interferon; IL, interleukin; IRAKM, IL-1R-associated kinase M; LAG3, lymphocyte activation gene 3; NLRX1, NOD-like receptor X1; PD1, programmed cell death 1; RNF125, ring finger containing domain 125; RLR, RIG-I-like receptor; SOCS, suppressor of cytokine signalling; TGF $\beta$, transforming growth factor- $\beta$; TIM3, T cell immunoglobulin domain and mucin domain protein 3; TLR, Toll-like receptor; TNF, tumour necrosis factor; $T_{\text {Reg }}$, regulatory $T$.

Latent infection

A dormant infection with a microorganism that persists in

the body for a long period of time, but it can be reactivated under certain conditions, such as immunosuppression.

Shingles

A viral disease characterized by painful, blistering skin rashes due to infection or recurrence of infection with varicella zoster virus.
Age of infection. Whether a virus causes severe tissue damage often depends on the age at which infection occurs. For example, intrauterine infections may result in severe tissue damage, as happens following rubella virus and $\mathrm{CMV}$ infections in humans ${ }^{75}$. In general, it is the young and the elderly who suffer the most severe consequences of infection, as shown by increased morbidity and mortality among these age groups following infection with seasonal influenza virus ${ }^{76}$. Increased susceptibility of the young, especially neonates, has been attributed to immature responsiveness of the immune system, particularly components of innate immunity. For example, RSV is usually the first pathogen that a human infant encounters and clinical signs of RSV infection are common by $2-3$ months of age ${ }^{77}$. Premature infants are particularly prone to develop severe lesions in the respiratory tract following RSV infection and these account for many of the 3-5\% of childhood RSV infections that require hospitalization ${ }^{77,78}$. This high susceptibility of infants to RSV-induced immunopathology is mainly explained by an inadequate type I IFN response together with a failure to activate subsets of DCs that induce $\mathrm{CD}^{+} \mathrm{T}$ cell- and $\mathrm{T}_{\mathrm{H}} 1$ cell-mediated protective responses $^{79}$. Instead, the DCs that are stimulated tend to produce IL-10 and TGF $\beta$ and induce the generation of FOXP3 ${ }^{+} \mathrm{T}_{\text {Reg }}$ cells $^{80}$. Studies of RSV infection using animal model systems indicate that the main mediators of the lung pathology are T cells, but there is still debate as to which subsets are primarily involved. Some studies indicate a pathological role for TNF-producing $\mathrm{CD}^{+}$ $\mathrm{T}$ cells, whereas other studies advocate that lesions are associated with $\mathrm{T}_{\mathrm{H}} 2$ cell-dominated responses ${ }^{16}$ (reviewed in REF. 78). Because childhood infection with RSV is a notable health problem, against which there is no effective vaccine, understanding at a mechanistic level why some individuals develop severe lesions to RSV is an important issue.

Aged individuals may also suffer more problems than younger individuals following primary or secondary infection with some viruses. For example, re-exposure of aged individuals to RSV can cause lesions similar to those that occur in infants ${ }^{81}$. In addition, aged individuals may develop lesions following reactivation of latent infections that had been successfully controlled by their immune system for decades. The best example of this is shingles, which is characterized by painful inflammatory skin lesions that occur at sites innervated by a sensory ganglion in which varicella zoster virus has been reactivated from latency ${ }^{82}$. It is not clear why this happens in only a few of the many ganglia that contain latent virus. It is possible that reactivation of latent virus occurs often but is successfully controlled by $\mathrm{T}$ cell immunity ${ }^{83}$. Presumably this $\mathrm{T}$ cell activity can fail at some sites but not others; further study is required to understand how this happens.

Understanding senescence of the immune system is an active area of research and the topic has been covered in excellent reviews ${ }^{84,85}$. Studies, mainly done in mice, have revealed that ageing has a greater effect on primary than on memory immune responses ${ }^{84}$. The T and $\mathrm{B}$ cells from aged individuals respond less well to antigens and are compromised in their ability to carry out effector functions compared with responses in young individuals. Moreover, naive $\mathrm{T}$ cells from aged compared with young animals undergo less homeostatic proliferation, probably because of competition with memory $\mathrm{T}$ cells for growth factors and anatomical space ${ }^{84}$. An additional effect observed during senescence is that the breadth of the $\mathrm{T}$ cell repertoire is reduced, perhaps because the thymus has involuted ${ }^{84}$. Indeed, compared with young individuals, aged individuals often have increased numbers of $\mathrm{CD}^{+} \mathrm{T}$ cells that recognize latent viral infections, particularly CMV infections - an effect known as memory inflation ${ }^{86}$. These CMV-specific CD8 ${ }^{+} \mathrm{T}$ cells can account for $50 \%$ or more of the total $\mathrm{CD} 8^{+}$memory $\mathrm{T}$ cell population. The space such cells occupy could diminish the number of lymphocytes available to react to pathogens, perhaps explaining why infections such as influenza virus are more severe in the elderly.

Dose and route of infection. As can readily be shown in experimental systems, the dose and route of transmitted virus can markedly influence the outcome of a virus infection. Minimal doses may be controlled subclinically by innate defences and may be insufficient to induce adaptive immune responses. Massive doses can overwhelm immune defences and cause severe disease and rapid death, in some instances by direct 


\section{Box 2 | Regulators of innate immune cells}

After recognizing pathogen-associated molecular patterns (PAMPs) through their innate receptors (such as Toll-like receptors (TLRs), RIG-I-like receptors (RLRs) and NOD-like receptors (NLRs), innate immune cells become activated and produce numerous inflammatory cytokines, including type I interferons, tumour necrosis factor (TNF), interleukin-6 (IL-6), IL-1 $\beta$ and some chemokines. Some of these molecules recruit other inflammatory cells such as neutrophils, which promote tissue damage. However, the host has evolved mechanisms to counter-regulate some or all of these pathways. Some of the important molecules and pathways include A20 deubiquitinase, IL-1R-associated kinase M (IRAKM), Toll-interacting proteins (TOLLIPs), suppressor of cytokine signalling (SOCS) proteins and myeloid cell-associated immunoglobulin-like receptors (MAIRs; also known as CD300 and TAM receptors). Some of these negative signalling systems affect innate immune responses to virus infections. For example, A20 terminates nuclear factor- $\kappa B$ signalling and IRAKM inhibits TLR and IL-1 $\beta$-induced signalling ${ }^{58}$. SOCS proteins inhibit cytokine signalling and are induced as a result of IL-10 receptor and TAM receptor signalling in macrophages and granulocytes. However some viruses use such pathways for their entry and enhanced tissue tropism. For example, filoviruses (such as Ebola virus and Marburg virus) exploit TAM receptors. After infection with filoviruses, innate cells secrete high levels of pro-inflammatory cytokines, such as type I IFNs. However, SOCS proteins are also induced as a result of TAM signalling ${ }^{140}$. Therefore, it is possible that although the use of these receptors by some viruses promotes infection and causes damage to the host, the subsequent signalling events induced might also moderate immunemediated tissue damage. This scenario, however, needs to be formally investigated in the pathogenesis of viral infections.
Innate receptors

The receptors that are present either on the surface or in the cytoplasm of innate immune cells that recognize microbial surface patterns or their replicative products and induce cytokine production. cytotoxic effects of viral components. Doses between these extremes can have a variable outcome from undetectable infection to tissue-damaging lesions. This issue has received surprisingly little formal study with virus infections, but it is a common practice for those who study viral pathogenesis to choose optimal doses of infection to evaluate their concepts. The dose and route of infection is expected to influence how successful the virus will be in gaining access to susceptible target cells and being transported by different types of DC to lymphoid tissues. Thus, it is clear from studies with protein antigens that the magnitude and quality of immune responses induced is influenced by the type of DCs that engage antigen ${ }^{87}$. With replicating agents such as viruses, dose effects might depend on the type of virus, the rates of replication and the virus-intrinsic properties such as expression of ligands for host innate immune receptors. For example, the dose of lentiviruses seems to have little effect, perhaps because potent infection is usually established by a single (founder) virion from the large numbers of virions (up to $10^{6}$ ) that are transmitted to the host ${ }^{88}$. Experimental studies of simian immunodeficiency virus (SIV) infection of macaques also show little or no effect of dose on the outcome of infection ${ }^{89}$. By contrast, for cytopathic viruses, the dose of infection can influence the response pattern ${ }^{90}$. It is curious that for influenza virus, the dose of infection of mice also affects the range of cells that become infected, as well as the balance of the immune response that results ${ }^{91}$. At high doses of virus, DCs and alveolar epithelial cells become infected. Moreover, the infected DCs deliver apoptotic signals to $\mathrm{CD} 8^{+} \mathrm{T}$ cells, which are normally necessary for resolving infection. At lower doses of virus, DC infection does not occur and the protective $\mathrm{CD}^{+} \mathrm{T}$ cell response is not compromised.
Recently, an interesting and unexpected effect of infection dose was observed in chimpanzees infected with $\mathrm{HBV}^{92}$. $\mathrm{HBV}$ is a non-cytopathic virus, and both control of the virus and the development of immunopathological hepatic lesions are mediated by $\mathrm{CD}^{+}$ $\mathrm{T}$ cells. Over a wide dose range $\left(10^{4}-10^{8}\right.$ virions $)$, the outcome of infection was similar, being controlled successfully 6-8 weeks after infection with minimal hepatitis. However, after administering a large dose $\left(>10^{8}\right)$ of virus, $100 \%$ of hepatocytes became infected, the virus reached high levels for at least 16 weeks and the animals developed chronic active hepatitis. Unexpectedly, animals infected with a very low dose (100 virons or less) had a comparable immunopathological outcome to those infected with a large dose. Reasons for this are still uncertain, but it is possible that at low doses the virus can go undetected by the immune system and fail to induce priming of $\mathrm{CD} 4^{+} \mathrm{T}$ cells, which are needed to provide help to mount a protective $\mathrm{CD} 8^{+} \mathrm{T}$ cell response. Furthermore, if animals were depleted of $\mathrm{CD} 4^{+} \mathrm{T}$ cells and given the medium dose of virus they developed chronic active hepatitis. How these observations relate to HBV infection of humans needs evaluation.

Dose of infection might explain the variable outcome observed following infection by insect-transmitted flaviviruses. The flavivirus West Nile virus is becoming a common infection in the Western hemisphere but most infected individuals do not suffer any clinical consequences. However some individuals develop a lifethreatening meningoencephalitis. In such individuals, the virus crosses the blood-brain barrier and lesions develop as a consequence of a viral antigen-specific T cellmediated immunopathological reaction to infected cells ${ }^{93}$. One hypothesis explaining the pathological outcome is that it occurs in circumstances in which the virus replicates rapidly and exceeds the host's ability to constrain it, despite the induction of a neutralizing antibody response and numbers of functional $\mathrm{T}$ cells that would otherwise be protective ${ }^{93}$. This scenario is more likely to occur in those exposed to many mosquito bites (providing a highdose infection), especially if the infected person is young, aged or has some degree of immunodeficiency. Curiously, some flaviviruses, including West Nile virus, stimulate TLR3 (which recognizes double-stranded DNA) and induce TNF production, and this may increase the permeability of the blood-brain barrier and allow entry of the virus to the $\mathrm{CNS}^{94}$.

The route of infection can also affect the extent of tissue damage that ensues. For example, with HSV infection of humans, oral or genital infection usually results in lesions that resolve without long-term damage. However, infection of the eye can result in chronic inflammatory lesions that cause blindness ${ }^{95}$. Similarly, mice infected with corona virus or Theiler's murine encephalomyelitis virus can develop immunopathological lesions in the CNS, but this response only occurs if the virus is given intracerebrally or intranasally and fails to occur after systemic infection ${ }^{96,97}$. The meningitis that adult mice develop after LCMV infection occurs only if the virus is administered directly into the cerebrospinal fluid and is not evident if administered by other routes ${ }^{98}$. 
Influence of heterologous immunity. Heterologous immunity is the term used to describe the observation that exposure to one pathogen will generate an immune response against numerous antigenic epitopes derived from that pathogen some of which might cross-react with epitopes derived from other pathogens. Following infection with the second pathogen, the cross-reactive memory cells expand more rapidly and may dominate the overall response. However, this cross-reactive response may be of low avidity and poorly protective but may still be able to mediate tissue damage. These circumstances could explain the occurrence of severe disease (dengue haemorrhagic fever (DHF)) in a small minority of the 50 million people who are infected with dengue virus. DHF is characterized by a high fever, vascular leakage, hypotension, circulatory shock and some bleeding manifestations. It usually occurs in individuals who are already immune to one dengue virus strain and become infected with a heterologous strain. An initial explanation for the DHF syndrome was that it occurred because cross-reactive, but non-neutralizing, antibodies opsonized the virus, facilitating uptake by macrophages ${ }^{99}$. This was proposed to result in immune activation, abundant production of cytokines and vascular leakage. Other investigators now suggest that $\mathrm{T}$ cells are the main orchestrators of the disease and that they cross-react with epitopes primed by exposure to a different viral strain ${ }^{99}$. The expanded $\mathrm{T}$ cell populations are not protective but they can mediate a severe inflammatory reaction that includes the production of vascular endothelial growth factor A (VEGFA), the main mediator of vascular leakage. DHF does not occur as often as might be expected on the basis of this mechanism, which suggests that additional factors are also involved. These include viral virulence, the ability to replicate efficiently and host genetic factors. Clinical and experimental evidence for the proposed pathogenesis of DHF is reviewed in REF. 100.

Another tissue-damaging human disease that could be explained by the existence of heterologous immunity is infectious mononucleosis. The disease is debilitating and can last for weeks but it only occurs in a minority of usually young adults who have experienced a primary infection with EBV. In patients that develop infectious mononucleosis, there is a 5-20 fold increase their circulating T cells, most of which are viral antigen-specific $\mathrm{CD}^{+}$ $\mathrm{T}$ cells. The pathogenesis of infectious mononucleosis is poorly understood but one provocative hypothesis is that the disease is the consequence of heterologous immunity, with infectious mononucleosis only occurring in individuals with EBV-cross-reactive T cells at the time of infection ${ }^{101}$. Such cross-reactive $\mathrm{T}$ cells are proposed to expand more rapidly than EBV-specific naive T cells induced following infection. However, the cross-reactive cells that dominate the response have low affinity for the virus antigen-expressing cells and cannot adequately control the infection, thereby setting the stage for chronic immunopathology. Supporting this concept, cross-reactivity between the influenza virus matrix protein and the EBV BMLF1 protein has been noted ${ }^{102}$. Experimental evidence that heterologous immunity can account for immunopathological responses in some but not all animals was provided by Kim and colleagues ${ }^{103}$. Other examples of cross-reactivity between different pathogens that influence disease patterns are reviewed in REF. 104.

Host genetics and the 'virome'. Variation in clinical responses of individuals to virus infections is influenced by the host genotype. Virulent infectious agents are assumed to have helped to shape our genome and are responsible for the extreme polymorphisms of many loci involved in MHC antigen processing and presentation $^{105}$. There is evidence that the outcome of the virus infection is affected by the HLA alleles expressed ${ }^{106}$, but the influence is usually modest. Thus, resistance to pathogens, including viruses, is directed by several genes that act at different stages of the virus-host interaction. For example, at least 250 genes are estimated to affect the outcome of infection by $\mathrm{HIV}^{107}$. As a result, the absence or malfunction of a single gene would probably have a negative or minimal effect on the outcome of a virus infection. Exceptions to this generalization include the primary immunodeficiencies that arise from rare monogenic defects and lead to increased susceptibility to various virus infections ${ }^{108}$. Mutations of genes encoding viral receptors and co-receptors can also influence disease susceptibility. For example, individuals with a homozygous 32 base pair deletion in CC-chemokine receptor 5 (CCR5, the entry co-receptor for X5 HIV) have greater resistance to HIV than heterozygous individuals ${ }^{109}$. Another example is that non-secretors of $\mathrm{ABO}$ blood groups are refractory to diarrhoea caused by Norwalk virus ${ }^{110}$. Mutations in genes that encode proteins involved in innate defence, such as the TLRs, can affect the clinical expression of some infections, but so far little has been reported for viruses. One example is a mutation in $U N C 93 B$, which encodes a transmembrane protein involved in TLR signalling ${ }^{111}$. Another is a loss of function mutation of TLR3 (REF. 74). Both defects result in defective cytokine production, especially IFNa and IFN $\beta$, in response to infection with HSV-1. Affected children develop herpes simplex encephalitis ${ }^{74,112}$ but, curiously, not other problems with HSV infection or other viruses.

A more common scenario that accounts for more severe disease following virus infection is polymorphisms in a few or many genes. Investigations on this topic have focused on HIV (reviewed in REFS 106,113) but most changes detected so far have been minor, probably because several genes affect resistance. Genetic factors have not yet been shown to explain the finding that $\sim 1 \%$ of HIV-infected patients control their infection long term without treatment ${ }^{114}$.

In addition to host genetics affecting the pattern of disease, other sources of genetic material in the host could influence the outcome of infection. These are the endogenous retrovirus elements, some of which are transcriptionally active, that are estimated to contribute to $8-9 \%$ of total human DNA ${ }^{115}$. The other sources are exogenous viruses that establish persistent infections and are mainly not retroviruses. According to a recent review, every individual may harbour several (8-12) different chronic asymptomatic viral infections that lie 


\section{Virome}

The total virus-derived genetic material present in the host owing to integrated or persistent exogenous viruses. undetected ${ }^{59}$. Together these endogenous and exogenous viruses have been referred to as the 'virome ${ }^{59}$. Already it is known that endogenous retroviruses could help to shape the $\mathrm{T}$ cell repertoire, deleting some specificities and expanding others ${ }^{116}$. Resident exogenous viruses might also influence the $\mathrm{T}$ cell repertoire and the activity status of the innate immune system, causing, for example, the production of cytokines and altered antigen presentation efficiency of DCs, but this needs to be formally shown. These effects will influence the balance of the response by individuals to exogenous agents. With technological advances in detecting both host gene polymorphisms and the virome, we anticipate that the influence of these factors on the outcome of virus infection will soon be better understood. This knowledge might provide clues to customize successful preventative and therapeutic approaches for viral infection and associated immunopathology.

\section{Conclusions}

Whether a virus infection results in severe, sometimes prolonged, lesions or is resolved with minimal bystander tissue damage depends on numerous factors. Some viruses (for example, HIV and HCV) have intrinsic properties that make immune control difficult, and attempts by the host immune system to achieve control results in notable tissue damage. Other infectious agents (for example, many herpesviruses) are successfully controlled in most individuals, but tissue damage occurs in those individuals that have predisposing genetic or acquired problems affecting one or more components of innate or adaptive immune system. Finally, some infections that are normally well controlled can cause extensive tissue damage under unusual circumstances. These might relate to the dose or route of exposure, the age of infection, host genetics and priming with cross-reacting viruses or co-infection with other agents.
Munz, C., Lunemann, J. D., Getts, M. T. \& Miller, S. D. Antiviral immune responses: triggers of or triggered by autoimmunity? Nature Rev. Immunol. 9, 246-258 (2009).

2. de Martel, C. \& Franceschi, S. Infections and cancer: established associations and new hypotheses. Crit. Rev. Oncol. Hematol. 70, 183-194 (2009).

3. Tal, M. C. et al. Absence of autophagy results in reactive oxygen species-dependent amplification of RLR signaling. Proc. Natl Acad. Sci. USA 106, 2770-2775 (2009).

4. Pichlmair, A. $\&$ Reis e Sousa, C. Innate recognition of viruses. Immunity 27, 370-383 (2007)

5 Iwasaki, A. \& Medzhitov, R. Toll-like receptor control of the adaptive immune responses. Nature Immunol. 5, 987-995 (2004).

6. Brooks, D. G. et al. Interleukin-10 determines viral clearance or persistence in vivo. Nature Med 12 1301-1309 (2006)

This paper implicated the role of IL-10 in the persistence of LCMV infection of mice and showed the therapeutic value of its neutralization in achieving viral control.

7. Brady, M. T., MacDonald, A. J., Rowan, A. G. \& Mills, K. H. Hepatitis C virus non-structural protein 4 suppresses Th1 responses by stimulating IL-10 production from monocytes. Eur. J. Immunol. 33 3448-3457 (2003).

8. Hyodo, N., Nakamura, I. \& Imawari, M. Hepatitis B core antigen stimulates interleukin- 10 secretion by both $\mathrm{T}$ cells and monocytes from peripheral blood of patients with chronic hepatitis B virus infection. Clin. Exp. Immunol. 135, 462-466 (2004).

9. Brockman, M. A et al. IL-10 is up-regulated in multiple cell types during viremic HIV infection and reversibly inhibits virus-specific T cells. Blood $\mathbf{1 1 4}$, 346-356 (2009)

10. Smit, J. J., Rudd, B. D. \& Lukacs, N. W. Plasmacytoid dendritic cells inhibit pulmonary immunopathology and promote clearance of respiratory syncytial virus. J. Exp. Med. 203, 1153-1159 (2006).

11. Guidotti, L. G. et al. Viral clearance without destruction of infected cells during acute HBV infection. Science 284, 825-829 (1999).

12. Rehermann, B. Hepatitis $C$ virus versus innate and adaptive immune responses: a tale of coevolution and coexistence. J. Clin. Invest. 119, 1745-1754 (2009).

13. Favre, D. et al. Critical loss of the balance between Th1 17 and T regulatory cell populations in pathogenic SIV infection. PLoS Pathog. 5, e1000295 (2009). This paper showed that $T_{H} 17$ cells are induced after SIV infection and that the balance of $T_{H} 17$ and $T_{\text {Reg }}$ cells is a crucial determinant in the progression of disease in pigtailed macaques but not in African green monkeys, in which $\mathrm{T}_{\mathrm{H}} 17$ cells were progressively depleted by the virus.

14. Rowan, A. G. et al. Hepatitis C virus-specific Th 17 cells are suppressed by virus-induced TGF- $\beta$. J. Immunol. 181, 4485-4494 (2008).
This is the first study to show that viral antigen-specific $T_{H} 17$ cells are induced in HCV-infected individuals and that viral protein (NS4)-induced TGF $\beta$ can inhibit the activity of $T_{H} 17$ cells.

15. Bermejo-Martin, J. F. et al. Th1 and Th17 hypercytokinemia as early host response signature in severe pandemic influenza. Crit. Care 13, R201 (2009).

16. Culley, F. J., Pennycook, A. M., Tregoning, J. S., Hussell, T. \& Openshaw, P. J. Differential chemokine expression following respiratory virus infection reflects Th1- or Th2-biased immunopathology. J. Virol. 80 4521-4527 (2006)

17. Ravetch, J. In vivo veritas: the surprising roles of Fc receptors in immunity. Nature Immunol. 11, 183-185 (2010).

18. Buchmeier, M. J. \& Oldstone, M. B. Virus-induced immune complex disease: identification of specific viral antigens and antibodies deposited in complexes during chronic lymphocytic choriomeningitis virus infection. J. Immunol. 120, 1297-1304 (1978). This is the first report in which immune complex deposits were measured using sensitive immunofluorescence and radioimmunoprecipitation in the tissue sites after a viral infection.

19. Nowoslawski, A., Krawczynski, K., Nazarewicz, T. \& Slusarczyk, J. Immunopathological aspects of hepatitis type B. Am. J. Med. Sci. 270, 229-239 (1975).

20. Johnson, R. J. et al. Membranoproliferative glomerulonephritis associated with hepatitis $C$ virus infection. N. Engl. J. Med. 328, 465-470 (1993).

21. Kimmel, P. L. et al. Brief report: idiotypic IgA nephropathy in patients with human immunodeficiency virus infection. N. Engl. J. Med. 327, 702-706 (1992)

22. Dakhama, A. et al. Virus-specific lgE enhances airway responsiveness on reinfection with respiratory syncytial virus in newborn mice. J. Allergy Clin. Immunol 123, 138-145 (2009).

23. Couper, K. N., Blount, D. G. \& Riley, E. M. IL-10: the master regulator of immunity to infection. J. Immunol. 180, 5771-5777 (2008).

24. Vieira, P. et al. Isolation and expression of human cytokine synthesis inhibitory factor cDNA clones: homology to Epstein-Barr virus open reading frame BCRFI. Proc. Natl Acad. Sci. USA 88, 1172-1176 (1991).

25. Kotenko, S. V., Saccani, S., Izotova, L. S. Mirochnitchenko, O. V. \& Pestka, S. Human cytomegalovirus harbors its own unique IL-10 homolog (cmvlL-10). Proc. Natl Acad. Sci. USA 97 1695-1700 (2000)

26. Moore, K. W., de Waal Malefyt, R., Coffman, R. L. \& O'Garra, A. Interleukin-10 and the interleukin-10 receptor. Annu. Rev. Immunol. 19, 683-765 (2001).

27. Sarangi, P. P., Sehrawat, S., Suvas, S. \& Rouse, B. T. IL-10 and natural regulatory T cells: two independent anti-inflammatory mechanisms in herpes simplex virus-induced ocular immunopathology. J. Immunol. 180, 6297-6306 (2008).
28. Mangia, A. et al. IL-10 haplotypes as possible predictors of spontaneous clearance of HCV infection. Cytokine 25, 103-109 (2004).

29. Naicker, D. D. et al. Interleukin-10 promoter polymorphisms influence HIV-1 susceptibility and primary HIV-1 pathogenesis. J. Infect. Dis. 200, 448-452 (2009)

30. Sun, J., Madan, R., Karp, C. L. \& Braciale, T. J. Effector $T$ cells control lung inflammation during acute influenza virus infection by producing IL-10 Nature Med. 15, 277-284 (2009). This study showed that by making IL-10, effector $\mathrm{CD}^{+} \mathrm{T}$ cells limit the extent of pulmonary tissue damage.

31. Elrefaei, M. et al. HIV-specific IL-10-positive CD8 T cells suppress cytolysis and IL- 2 production by CD8+ T cells. J. Immunol. 178, 3265-3271 (2007).

32. Kobasa, D. et al. Aberrant innate immune response in lethal infection of macaques with the 1918 influenza virus. Nature 445, 319-323 (2007).

33. Li, M. O. \& Flavell, R. A. Contextual regulation of inflammation: a duet by transforming growth factor- $\beta$ and interleukin-10. Immunity 28, 468-476 (2008).

34. Li, M. O. \& Flavell, R. A. TGF- $\beta$ : a master of all T cell trades. Cell 134, 392-404 (2008).

35. Aung, H., Wu, M., Johnson, J. L., Hirsch, C. S. \& Toossi, Z. Bioactivation of latent transforming growth factor $\beta 1$ by Mycobacterium tuberculosis in human mononuclear phagocytes. Scand. J. Immunol. 61, 558-565 (2005)

36. Omer, F. M., de Souza, J. B., Corran, P. H., Sultan, A. A. \& Riley, E. M. Activation of transforming growth factor $\beta$ by malaria parasite-derived metalloproteinases and a thrombospondin-like molecule. J. Exp. Med. 198, 1817-1827 (2003).

37. Schultz-Cherry, S. \& Hinshaw, V. S. Influenza virus neuraminidase activates latent transforming growth factor $\beta$. J. Virol. 70, 8624-8629 (1996).

38. Beckham, J. D., Tuttle, K. \& Tyler, K. L. Reovirus activates transforming growth factor $\beta$ and bone morphogenetic protein signaling pathways in the central nervous system that contribute to neuronal survival following infection. J. Virol. 83, 5035-5045 (2009).

39. Alatrakchi, N. et al. Hepatitis C virus (HCV)-specific $\mathrm{CD} 8{ }^{+}$cells produce transforming growth factor $\beta$ that can suppress HCV-specific T-cell responses. J. Virol. 81, 5882-5892 (2007)

40. Tinoco, R., Alcalde, V., Yang, Y., Sauer, K. \& Zuniga, E. I. Cell-intrinsic transforming growth factor- $\beta$ signaling mediates virus-specific $\mathrm{CD} 8{ }^{+} \mathrm{T}$ cell deletion and viral persistence in vivo. Immunity 31, 145-157 (2009).

This report showed that TGF $\beta$ functions intrinsically to limit $C D 8^{+} \mathrm{T}$ cell responses to viral infection.

41. O'Connor, W. Jr et al. A protective function for interleukin 17A in T cell-mediated intestinal inflammation. Nature Immunol. 10, 603-609 (2009). 
42. Hou, W., Kang, H. S. \& Kim, B. S. Th17 cells enhance viral persistence and inhibit T cell cytotoxicity in model of chronic virus infection. J. Exp. Med. 206 313-328 (2009)

43. Rabinovich, G. A. \& Toscano, M. A. Turning 'sweet' on immunity: galectin-glycan interactions in immune tolerance and inflammation. Nature Rev. Immunol. 9, 338-352 (2009).

44. Zhu, C. et al. The Tim-3 ligand galectin-9 negatively regulates T helper type 1 immunity. Nature Immunol. 6. 1245-1252 (2005)

45. Sehrawat, S., Suryawanshi, A., Hirashima, M. \& Rouse, B. T. Role of Tim-3/galectin-9 inhibitory interaction in viral-induced immunopathology: shifting the balance toward regulators. J. Immunol. 182 3191-3201 (2009).

This paper showed that galectin 9 could promote FOXP3 ${ }^{+} T_{\text {Reg }}$ cell responses and that ligation of TIM3 with galectin 9 induces apoptosis of effector $T$ cells but not $T_{\text {eel }}$ cells.

46. Sehrawat, S., Reddy, P. B. J., Rajasagi, N Suryawanshi, A., Hirashima, M. \& Rouse, B. T. Galectin-9/TIM-3 interaction regulates virus-specific primary and memory $\mathrm{CD}^{+} \mathrm{T}$ cell response. PLoS Pathog. 6, e1000882 (2010).

47. Chagan-Yasutan, H. et al. Persistent elevation of plasma osteopontin levels in HIV patients despite highly active antiretroviral therapy. Tohoku J. Exp. Med. 218, 285-92 (2009).

48. Mengshol, J. A et al A crucial role for kupffer cellderived galectin-9 in regulation of $\mathrm{T}$ cell immunity in hepatitis C infection. PLOS ONE 5, e9504 (2010).

49. Sakaguchi, S. Regulatory T cells: key controllers of immunologic self-tolerance. Cell 101, 455-458 (2000).

50. Belkaid, Y. \& Tarbell, K. Regulatory T cells in the control of host-microorganism interactions. Annu. Rev. Immunol. 27, 551-589 (2009).

51. Suvas, S., Azkur, A. K., Kim, B. S., Kumaraguru, U. \& Rouse, B. T. CD $4{ }^{+} \mathrm{CD} 25^{+}$regulatory T cells control the severity of viral immunoinflammatory lesions. J. Immunol. 172, 4123-4132 (2004)

52. Ruckwardt, T. J., Bonaparte, K. L., Nason, M. C. \& Graham, B. S. Regulatory T cells promote early influx of $C D 8+T$ cells in the lungs of respiratory syncytial virus-infected mice and diminish immunodominance disparities. J. Virol. 83, 3019-3028 (2009).

53. Lanteri, M. C. et al. Tregs control the development of symptomatic West Nile virus infection in humans and mice. J. Clin. Invest. 119, 3266-3277 (2009).

54. Sehrawat, S., Suvas, S., Sarangi, P. P., Suryawanshi, A $\&$ Rouse, B. T. In vitro-generated antigen-specific $\mathrm{CD}^{+}{ }^{+} \mathrm{CD} 25^{+}$Foxp3 + regulatory T cells control the severity of herpes simplex virus-induced ocular immunoinflammatory lesions. J. Virol 82 6838-6851 (2008)

55. Sehrawat, S. \& Rouse, B. T. Anti-inflammatory effects of FTY720 against viral-induced immunopathology: role of drug-induced conversion of T cells to become Foxp3+ regulators. J. Immunol. 180, 7636-7647 (2008).

56. Rouse, B. T., Sarangi, P. P. \& Suvas, S. Regulatory $\mathrm{T}$ cells in virus infections. Immunol. Rev. 212 272-286 (2006)

57 MacDonald, A J et al. CD4 T helper type 1 and regulatory $T$ cells induced against the same epitopes on the core protein in hepatitis C virus-infected persons. J. Infect. Dis. 185, 720-727 (2002). This report showed that induction of T regulatory 1 cells in patients infected with HCV negatively correlated with the extent of liver damage.

58. Liew, F. Y., Xu, D., Brint, E. K. \& O'Neill, L. A. Negative regulation of Toll-like receptor-mediated immune responses. Nature Rev. Immunol. 5, 446-458 (2005)

59. Virgin, H. W. Wherry, E. J. \& Ahmed, R. Redefining chronic viral infection. Cell 138, 30-50 (2009).

60. Barber, D. L. et al. Restoring function in exhausted CD8 T cells during chronic viral infection. Nature 439 682-687 (2006)

This seminal paper showed that the functional T cell exhaustion caused by a chronic viral infection could be reversed using antibody specific for the inhibitory molecule PD1.

61. Day, C. L. et al. PD-1 expression on HIV-specific T cells is associated with T-cell exhaustion and disease progression. Nature 443, 350-354 (2006) This report showed that antigen-specific CD8 $T$ cells isolated from patients with HIV expressed higher levels of the inhibitory molecule PD1 and that the exhaustion could be reversed, at least ex vivo, by using blocking antibody.
62. Radziewicz, H. et al. Liver-infiltrating lymphocytes in chronic human hepatitis $\mathrm{C}$ virus infection display an exhausted phenotype with high levels of PD-1 and low levels of CD127 expression. J. Virol. 81, 2545-2553 (2007).

63. Maier, H., Isogawa, M., Freeman, G. J. \& Chisari, F. V. PD-1:PD-L1 interactions contribute to the functional suppression of virus-specific CD8 ${ }^{+} \mathrm{T}$ lymphocytes in the liver. J. Immunol. 178, 2714-2720 (2007)

64. Said, E. A. et al. Programmed death-1-induced interleukin-10 production by monocytes impairs CD4 ${ }^{+}$ T cell activation during HIV infection. Nature Med. 16, 452-459 (2010)

65. Yao, Z. Q., King, E., Prayther, D., Yin, D. \& Moorman, J. $T$ cell dysfunction by hepatitis $C$ virus core protein involves PD-1/PDL-1 signaling. Viral Immunol. 20 276-287 (2007)

66. Boasso, A. et al. PDL-1 upregulation on monocytes and T cells by HIV via type I interferon: restricted expression of type I interferon receptor by CCR5-expressing leukocytes. Clin. Immunol. 129, 132-144 (2008).

67. Brooks, D. G. et al. IL-10 and PD-L1 operate through distinct pathways to suppress T-cell activity during persistent viral infection. Proc. Natl Acad. Sci. USA 105, 20428-20433 (2008)

68. Blackburn, S. D. et al. Coregulation of $\mathrm{CD}^{+} \mathrm{T}$ cell exhaustion by multiple inhibitory receptors during chronic viral infection. Nature Immunol. 10, 29-37 (2009)

69. Brooks, D G., Lee, A. M., Elsaesser, H., McGavern, D. B. \& Oldstone, M. B. IL-10 blockade facilitates DNA vaccine-induced $T$ cell responses and enhances clearance of persistent virus infection. J. Exp. Med 205, 533-541 (2008)

70. Ha, S. J. et al. Enhancing therapeutic vaccination by blocking PD-1-mediated inhibitory signals during chronic infection. J. Exp. Med. 205, 543-555 (2008)

71. Racaniello, V. R. One hundred years of poliovirus pathogenesis. Virology 344, 9-16 (2006).

72. Whitley, R. J. Herpes Simplex Viruses (eds Knipe, D. M ¿ Howley, P. M.) (Lippincott Williams \& Wilkins, New York, 2001)

73. Tabeta, K. et al. The Unc93b1 mutation $3 \mathrm{~d}$ disrupts exogenous antigen presentation and signaling via Toll-like receptors 3, 7 and 9. Nature Immunol. 7, 156-164 (2006)

74. Zhang, S. Y. et al. TLR3 deficiency in patients with herpes simplex encephalitis. Science 317 1522-1527 (2007).

75. McIntosh, E. D. Paediatric infections: prevention of transmission and disease - implications for adults. Vaccine 23, 2087-2089 (2005).

76. Rothberg, M. B., Haessler, S. D. \& Brown, R. B. Complications of viral influenza. Am. J. Med. 121, 258-264 (2008)

77. Tregoning, J. S. \& Schwarze, J. Respiratory viral infections in infants: causes, clinical symptoms, virology, and immunology. Clin. Microbiol Rev. 23, 74-98 (2010).

78. Collins, P. L. \& Graham, B. S. Viral and host factors in human respiratory syncytial virus pathogenesis. J. Virol. 82, 2040-2055 (2008).

79. Spann, K. M., Tran, K. C., Chi, B., Rabin, R. L. $\delta$ Collins, P. L. Suppression of the induction of $\alpha, \beta$, and $\lambda$ interferons by the NS1 and NS2 proteins of human respiratory syncytial virus in human epithelial cells and macrophages. J. Virol. 78, 4363-4369 (2004)

80. Smit, J. J. et al. The balance between plasmacytoid $D C$ versus conventional $D C$ determines pulmonary immunity to virus infections. PLOS ONE 3, e1720 (2008)

81. Culley, F. J., Pollott, J. \& Openshaw, P. J. Age at first viral infection determines the pattern of T cellmediated disease during reinfection in adulthood. J. Exp. Med. 196, 1381-1386 (2002). The influence of age at first exposure to a viral infection on the susceptibility of the same infection later in the life was shown in a mouse model of RSV infection.

82. Whitley, R. J. A 70-year-old woman with shingles: review of herpes zoster. JAMA 302, 73-80 (2009).

83. Rouse, B. T. \& Kaistha, S. D. A tale of 2 alphaherpesviruses: lessons for vaccinologists. Clin. Infect. Dis. 42, 810-817 (2006).

84. Nikolich-Zugich, J. Ageing and life-long maintenance of T-cell subsets in the face of latent persisten infections. Nature Rev. Immunol. 8, 512-522 (2008).

85. Maue, A. C. et al. T-cell immunosenescence: lessons learned from mouse models of aging. Trends Immunol. 30, 301-305 (2009).
86. Snyder, C. M. et al. Memory inflation during chronic viral infection is maintained by continuous production of short-lived, functional T cells. Immunity 29, 650-659 (2008)

87. Schakel, K. Dendritic cells - why can they help and hurt us. Exp. Dermatol. 18, 264-273 (2009).

88. Haaland, R. E. et al. Inflammatory genital infections mitigate a severe genetic bottleneck in heterosexual transmission of subtype A and C HIV-1. PLoS Pathog. 5, e1000274 (2009).

89. McDermott, A. B. et al. Repeated low-dose mucosal simian immunodeficiency virus SIVmac239 challenge results in the same viral and immunological kinetics as high-dose challenge: a model for the evaluation of vaccine efficacy in nonhuman primates. J. Virol. 78 3140-3144 (2004).

90. Oh, S., McCaffery, J. M. \& Eichelberger, M. C Dose-dependent changes in influenza virus-infected dendritic cells result in increased allogeneic T-cell proliferation at low, but not high, doses of virus. J. Virol. 74, 5460-5469 (2000).

91. Legge, K. L. \& Braciale, T. J. Lymph node dendritic cells control $\mathrm{CD}^{+} \mathrm{T}$ cell responses through regulated FasL expression. Immunity 23, 649-659 (2005).

92. Asabe, S. et al. The size of the viral inoculum contributes to the outcome of hepatitis B virus infection. J. Virol. 83, 9652-9662 (2009). This study investigated the influence of dose of infecting HBV on the pathogenesis of liver disease and clearly showed that very high or very low doses of infection led to severe liver damage.

93. King, N. J. et al. Immunopathology of flavivirus infections. Immunol. Cell Biol. 85, 33-42 (2007).

94. Wang, T. et al. Toll-like receptor 3 mediates West Nile virus entry into the brain causing lethal encephalitis. Nature Med. 10, 1366-1373 (2004).

95. Koelle, D. M. \& Corey, L. Herpes simplex: insights on pathogenesis and possible vaccines. Annu. Rev. Med. 59, 381-395 (2008)

96. Weiner, L. P. Pathogenesis of demyelination induced by a mouse hepatitis. Arch. Neurol. 28, 298-303 (1973).

97. Fazakerley, J. K. \& Walker, R. Virus demyelination. J. Neurovirol 9, 148-164 (2003).

98. Cole, G. A., Nathanson, N. \& Prendergast, R. A. Requirement for $\theta$-bearing cells in lymphocytic choriomeningitis virus-induced central nervous system disease. Nature 238, 335-337 (1972)

99 Halstead, S. B. Dengue. Lancet 370, 1644-1652 (2007).

100. Mathew, A. \& Rothman, A. L. Understanding the contribution of cellular immunity to dengue disease pathogenesis. Immunol. Rev. 225, 300-313 (2008).

101. Hadinoto, V. et al. On the dynamics of acute EBV infection and the pathogenesis of infectious mononucleosis. Blood 111, 1420-1427 (2008).

102. Clute, S. C. et al. Cross-reactive influenza virus-specific $\mathrm{CD}^{+} \mathrm{T}$ cells contribute to lymphoproliferation in Epstein-Barr virus-associated infectious mononucleosis. J. Clin. Invest. 115, 3602-3612 (2005).

This study showed that major contributors to infectious mononucleosis are cross-reactive $\mathrm{T}$ cells specific for a previously encountered virus.

103. Kim, S. K. et al. Private specificities of CD8 T cell responses control patterns of heterologous immunity. J. Exp. Med. 201, 523-533 (2005).

104 Welsh, R. M. \& Fujinami, R. S. Pathogenic epitopes, heterologous immunity and vaccine design. Nature Rev. Microbiol. 5, 555-563 (2007)

105. Segal, S. \& Hill, A. V. Genetic susceptibility to infectious disease. Trends Microbiol. 11, 445-448 (2003).

106. Goulder, P. J. \& Watkins, D. I. Impact of MHC class I diversity on immune control of immunodeficiency virus replication. Nature Rev. Immunol. 8, 619-630 (2008).

107. Brass, A L et al Identification of host proteins required for HIV infection through a functional genomic screen. Science 319, 921-926 (2008).

108. Good, R. A. \& Hansen, M. A. Primary immunodeficiency diseases. Adv. Exp. Med. Biol. 73, 155-178 (1976)

109. Liu, R. et al. Homozygous defect in HIV-1 coreceptor accounts for resistance of some multiply-exposed individuals to HIV-1 infection. Cell 86, 367-377 (1996).

10. Hill, A. V. Aspects of genetic susceptibility to human infectious diseases. Annu. Rev. Genet. 40, 469-486 (2006). 
111. Casrouge, A. et al. Herpes simplex virus encephalitis in human UNC-93B deficiency. Science 314 308-312 (2006)

112. Zhang, S. Y. et al. Inborn errors of interferon (IFN)mediated immunity in humans: insights into the respective roles of IFN- $\alpha / \beta$, IFN $-\gamma$, and IFN $-\lambda$ in host defense. Immunol. Rev. 226, 29-40 (2008).

113. Kaur, G. \& Mehra, N. Genetic determinants of HIV-1 infection and progression to AIDS: susceptibility to HIV infection. Tissue Antigens 73, 289-301 (2009).

114. Hubert, J. B. et al. Natural history of serum HIV-1 RNA levels in 330 patients with a known date of infection. The SEROCO Study Group. AIDS 14 123-131 (2000)

This study showed that some patients with HIV can control the virus for a long time without the need for antiretroviral therapy.

115. Seifarth, W. et al. Comprehensive analysis of human endogenous retrovirus transcriptional activity in human tissues with a retrovirus-specific microarray. J. Virol. 79, 341-352 (2005).

116. Lower, R., Lower, J. \& Kurth, R. The viruses in all of us: characteristics and biological significance of human endogenous retrovirus sequences. Proc. Natl Acad. Sci. USA 93, 5177-5184 (1996).

117. Wilkins, C. $\&$ Gale, M. Jr. Recognition of viruses by cytoplasmic sensors. Curr. Opin. Immunol. 22, 41-47 (2001).

118. York, I. A. et al. A cytosolic herpes simplex virus protein inhibits antigen presentation to $\mathrm{CD} 88^{+}-$ lymphocytes. Cell 77, 525-535 (1994).

119. Ahn, K. et al. Human cytomegalovirus inhibits antigen presentation by a sequential multistep process. Proc. Natl Acad. Sci. USA 93, 10990-10995 (1996)

120. Gilbert, M. J., Riddell, S. R., Plachter, B. \& Greenberg, P. D. Cytomegalovirus selectively blocks antigen processing and presentation of its immediate-early gene product. Nature 383, 720-722 (1996).

121. Levitskaya, J., Sharipo, A., Leonchiks, A., Ciechanover, A. \& Masucci, M. G. Inhibition of ubiquitin/proteasome-dependent protein degradation by the Gly-Ala repeat domain of the Epstein-Barr virus nuclear antigen 1. Proc. Natl Acad. Sci. USA 94, 12616-12621 (1997).
122. Koppelman, B., Neefjes, J. J., de Vries, J. E. \& de Waal Malefyt, R. Interleukin-10 down-regulates MHC class II $\alpha \beta$ peptide complexes at the plasma membrane of monocytes by affecting arrival and recycling. Immunity 7, 861-871 (1997).

123. Greenberg, M. E. et al. Co-localization of HIV-1 Nef with the AP-2 adaptor protein complex correlates with Nef-induced CD4 down-regulation. EMBO J. 16, 6964-6976 (1997)

124. Holmes, E. C. Evolutionary history and phylogeography of human viruses. Annu. Rev. Microbiol. 62, 307-328 (2008).

125. Devergne, O., Birkenbach, M. \& Kieff, E. Epstein-Barr virus-induced gene 3 and the p35 subunit of interleukin 12 form a novel heterodimeric hematopoietin. Proc. Natl Acad. Sci. USA 94, 12041-12046 (1997).

126. Moskophidis, D., Lechner, F., Pircher, H. \& Zinkernagel, R. M. Virus persistence in acutely infected immunocompetent mice by exhaustion of antiviral cytotoxic effector T cells. Nature 362, 758-761 (1993).

127. Periwal, S. B. \& Cebra, J. J. Respiratory mucosal immunization with reovirus serotype $1 / \mathrm{L}$ stimulates virus-specific humoral and cellular immune responses, including double-positive $\left(\mathrm{CD}^{+} / \mathrm{CD}^{+}\right) \mathrm{T}$ cells. J. Virol. 73, 7633-7640 (1999).

128. Fulton, J. R., Smith, J., Cunningham, C. \& Cuff, C. F. Influence of the route of infection on development of T-cell receptor $\beta$-chain repertoires of reovirus-specific cytotoxic T lymphocytes. J. Virol. 78, 1582-1590 (2004)

129. Le Goffic, R. et al. Detrimental contribution of the Tolllike receptor (TLR)3 to influenza A virus-induced acute pneumonia. PLoS Pathog. 2, e53 (2006).

130. Bochud, P. Y., Magaret, A. S., Koelle, D. M., Aderem, A. \& Wald, A. Polymorphisms in TLR2 are associated with increased viral shedding and lesional rate in patients with genital herpes simplex virus type 2 infection. J. Infect. Dis. 196, 505-509 (2007)

131. Almarri, A. \& Batchelor, J. R. HLA and hepatitis B infection. Lancet 344, 1194-1195 (1994).

132. Gao, X. et al. AIDS restriction HLA allotypes target distinct intervals of HIV-1 pathogenesis. Nature Med. 11, 1290-1292 (2005)
133. Fellay, J. et al. A whole-genome association study of major determinants for host control of HIV-1. Science 317, 944-947 (2007)

134. Fanning, L. J. et al. HLA class II genes determine the natural variance of hepatitis $C$ viral load. Hepatology $33,224-230$ (2001)

135. Thomas, D. L. et al. Genetic variation in IL28B and spontaneous clearance of hepatitis C virus. Nature 461, 798-801 (2009).

136. Ge, D. et al. Genetic variation in IL28B predicts hepatitis $C$ treatment-induced viral clearance. Nature 461, 399-401 (2009).

137. Knapp, S. et al. Polymorphisms in interferon-induced genes and the outcome of hepatitis $C$ virus infection: roles of MxA, OAS- 1 and PKR. Genes Immun. 4, 411-419 (2003)

138. Monto, A. S. Epidemiology of influenza. Vaccine 26 D45-D48 (2008).

139. Peebles, R. S. Jr \& Graham, B. S. Pathogenesis of respiratory syncytial virus infection in the murine model. Proc. Am. Thorac Soc. 2, 110-115 (2005).

140. Lemke, G. \& Rothlin, C. V. Immunobiology of the TAM receptors. Nature Rev. Immunol. 8, 327-336 (2008).

Acknowledgements

We thank D. Masopust and M. Sangster for valuable comments. The work was supported by US National Institutes of Health grants RO1 Al 106336501 and RO1 EY 05093.

Competing interests statement

The authors declare no competing financial interests.

DATABASES

UniProtKB: http://www.uniprot.org

FOXP3 | galectin 9 | IL-10 | LAG3 | PD1 | PDL1 | RIG-1| TIM3 |

TLR3 | TLR7 | TLR8 | TLR9 | TNF | UNC93B |VEGFA

FURTHER INFORMATION

Barry T. Rouse's homepage

http://www.vet.utk.edu/faculty/rouse.php

ALL LINKS ARE ACTIVE IN THE ONLINE PDF 